Sahel Journal of Veterinary Sciences

\author{
Article History \\ Received: 12-04-2020 \\ Revised: 08-09-2020 \\ Accepted: 13-09-2020 \\ Published: 29-09-2020
}

Copyright (C) 2020 Faculty of Veterinary Medicine, University of Maiduguri

\title{
Acute Canine Monocytic Ehrlichiosis and Sertoli Cell Tumour in an Eleven-Year-Old Dachshund Cross-Bred Dog
}

\author{
${ }^{1 *}$ Mustapha, R. A., ${ }^{2}$ Emmanuel, E. G., ${ }^{3}$ Lawal, M., ${ }^{3}$ Abdurrahman, M., ${ }^{4}$ Umaru-Sule, B., \\ ${ }^{1}$ Agbonika, S., ${ }^{3}$ Abodunrin, A. and ${ }^{6}$ Sambo., J.
}

\author{
${ }^{1}$ Department of Theriogenology and Production, Ahmadu Bello University, Zaria \\ ${ }^{2}$ Veterinary Teaching Hospital, Ahmadu Bello University, Zaria \\ ${ }^{3}$ Department of Veterinary Surgery and Radiology, Ahmadu Bello University, Zaria \\ ${ }^{4}$ Department of Veterinary Parasitology and Entomology, Ahmadu Bello University, Zaria \\ ${ }^{5}$ National Animal Production and Research Institute, Ahmadu Bello University, Zaria \\ ${ }^{6}$ Department of Veterinary Pathology, Ahmadu Bello University, Zaria.
}

*Author for Correspondence: rhyme4bee@gmail.com

\begin{abstract}
An eleven-year-old Dachshund cross-bred dog was presented to the Small Animal Clinic of Ahmadu Bello University Veterinary Teaching Hospital, Zaria, with complaints of reduced appetite noticed 2 days earlier, and an enlarged testis was noticed three months prior to presentation. Clinical diagnosis was based on history of reduced appetite and enlarged testis; physical findings such as pyrexia, tick infestation, congested ocular mucous membranes, generalized enlarged superficial lymph nodes, enlargement of the mammary glands, alopecia, atrophy of the right testis and discoloration of the scrotum with large, firm palpable mass; complete blood count revealed slight anaemia (PCV $34 \%$, neutrophilia (12.88 x 10\%/L) and presence of band cells $\left(0.32 \times 10^{9} / \mathrm{L}\right)$; buffy coat smear showed the presence of intracytoplasmic morulae in just one monocyte in the peripheral blood smear; Ehrlichia canis antibodies was detected in serum using Ehrlichia test kit (immunochromatography); serum oestradiol-17 $\beta(42.05 \mathrm{pg} / \mathrm{mL})$ and anti- Müllerian hormone (AMH; $25.50 \mu \mathrm{g} / \mathrm{mL})$ were employed as serum tumour markers; transverse and longitudinal scrotal sonographs revealed diffuse non-homogenous tissues with increase in the echogenicity of the testicles; radiographic findings of thoraco-abdomino-pelvic regions revealed normal organ opacity indicating absence of metastases. Tissue samples were taken from the tumor following surgical excision and submitted for histopathology. The findings were large cytoplasmic vacuoles with slightly irregular nucleoli. It was confirmed to be sertoli cell tumor. The conditions were managed medically, and by surgical excision of the tumour and scrotal ablation. Outcome was successful, and patient started feeding 24 hours after the surgery.
\end{abstract}

Key words: Castration; Buffy coat smear; Tumour markers; Testicular tumour; Scrotal ablation

\section{INTRODUCTION}

Sertoli cell tumour (SCT) is mostly a non-invasive tumour (Švara et al., 2014), and commonly found in older, un-neutered dogs. The likelihood of malignancy increases when the tumor occurs in testes that are retained within the abdominal or inguinal cavity (Liao et al., 2009; Hohsteter et al., 2014; Sivasudharsan et al., 2017), even in humans (Ferguson and Agoulnik, 2013), and less commonly with hermaphroditism (Herndon et al., 2012) and persistent Müllerian duct syndrome (Cahua et al., 2015; Zambarda et al., 2019). Metastasis from the extra-scrotal tumors is most common due to late diagnosis (Castro et al., 2016). Although rare, it may also occur in the ovary of females (Young 2005; Rabban et al., 2010; Priyadarshini et al., 2019). Frequently, estradiol- $17 \beta$ concentrations are significantly higher in dogs with this tumour (Tsuzuki et al., 2017), and these dogs have lower levels of testosterone than normal, but some few affected dogs with malignant SCT have been reported in contrary (Kang et al., 2011; Castro et al., 2016). In severe cases this may lead to bone marrow depression with resultant fatal pancytopenia, a condition in which the red blood cells, white blood cells and platelets values are below normal (Lawrence and Saba, 2013). More than $30 \%$ of dogs diagnosed with testicular cancer have more than one primary testicular tumour (Grieco et al., 2008). Diagnosis is based on history, clinical symptoms, determination of serum biomarkers of tumour (Holst and Dreimanis, 2015) and full blood count, which may reveal anaemia (Valente et al., 2017). Ultrasonography is employed as diagnostic imaging means, but can include radiography and CT or MRI, in order to exclude metastases. A definitive diagnosis is based on laparoscopic identification of retained testicular tumor and histological examination of biopsied, or 
sectioned tissue samples (Carreira et al., 2012). Immunohistochemistry may be used to further differentiate testicular tumors, using antibodies against anti-Müllerian hormone (Banco et al., 2012), LH receptors, 3 $\beta$-hydoxysteroid dehydrogenase, vimentin and cytokeratin (Hohsteter et al., 2014).

Canine monocytic ehrlichiosis (CME) is a tropical tick-borne disease caused by obligate intracellular bacteria of genus Ehrlichia of the family Rickettsiaceae. The most common cause of the clinical disease in dogs is Ehrlichia canis. CME is most commonly reported in areas with an increased concentration of Rhipicephalus sanguineus, the brown dog tick, such as Africa, Asia and India (Kukreti et al., 2018; Dhliwayo et al., 2019; Ybanez et al., 2019). Clinical findings in dogs vary with the phase of infection. Non-specific signs such as fever, anorexia, oculonasal discharge, depression, lymphadenopathy and weight loss may occur during the acute phase (Waner and Harrus, 2013). The diagnosis of CME using serology is a known gold standard, and is usually recommended when prophylactic exposure is ruled out (Harrus and Waner, 2011). The demonstration of Ehrlichia spp. morulae in monocytes, macrophages and lymphocytes in stained smears from whole blood or buffy coat, and less frequently in lymph node, bone marrow, spleen, liver and cerebrospinal fluid smears, is also helpful in establishing a definitive diagnosis of acute CME (Mylonakis et al., 2010; Harrus et al., 2012; Kaewmongkol et al., 2016). Although, doxycycline is highly recommended in management in acute or subclinical infections, it may invariably not be effective in completely eliminating E. canis infection in some chronic cases (Fourie et al., 2015; Schulz et al. 2011). The use of imidocarb dipropionate is indicated in dual infections with Babesia canis (Sainz et al., 2015).

\section{CASE PRESENTATION}

\section{Case History}

An 11-year-old Dachshund cross-bred dog weighing 18kg was presented at the Small Animal Clinic of Ahmadu Bello University Veterinary Teaching Hospital, Zaria, with the chief complaints of reduced appetite noticed 2 days earlier, and enlarged testis. The enlargement was first noticed 6 months prior time of presentation, and treatment had been attempted in two different veterinary clinics. Since acquired as a puppy, it has been the only animal in the house, and had been out of the house only twice. The dog had never been used for breeding; hence no contact with any female dog. Vaccination history (DHLPP and anti-rabies) was up-to-date.

\section{Clinical Evaluation}

Rectal temperature was $42^{\circ} \mathrm{C}$, while values of pulse and respiratory rates could not be obtained due to fibrillation and panting, respectively. Clinical findings included pyrexia, tick infestation, congested ocular mucous membranes, generalize enlarged superficial lymph nodes (submandibular, prescapular and popliteal), enlargement of the mammary glands, alopecia, atrophy of the right testis and discoloration of the scrotum with large, firm palpable mass in the left testis (Figure 1).

\section{Laboratory Investigations}

Full blood count, hormonal assay and determination of serum tumour markers, followed by sonographic and radiographic exposures were all requested as the clinical findings were suggestive of acute Canine ehrlichiosis, and feminization syndrome usually associated with estradiol-producing testicular tumour. Haematological profile, as described by Jain (1986), showed slight anaemia (PCV $34 \%$, as against the reference range of $37-55 \%$, neutrophilia $\left(12.88 \times 10^{9} / \mathrm{L}\right.$; reference range of $\left.3.0-11.54 \times 10^{9} / \mathrm{L}\right)$ and band neutrophils $0.32 \times 10^{9} / \mathrm{L}$ slightly above the $0.00-0.30 \times 10^{9} / \mathrm{L}$ normal range), suggestive of an on-going infection and, or, inflammation (Kottadamane et al., 2016). Other haematological parameters were within normal reference values.

Ehrlichiosis was suspected and diagnosed using lateral flow $\mathrm{i}$ mmunochromatographic) assay for detection of Ehrlichia canis antibodies in the serum sample using a commercial test kit containing plastic combs sensitized with E. canis antigen (Bionote INC., Seogu-dong, Republic of Korea). Buffy coat smear was also made with peripheral whole blood sample using Giemsa stain, and viewed by direct microscopic examination. The presence of intracytoplasmic morulae in just one monocyte in the peripheral blood smear examination confirmed the Ehrlichiosis (Figure 2). The ticks were identified as the dog brown tick, Rhipicephalus sanguineus.

Using radio-immunoassay as described by Hornakova et al. (2017), serum levels of estradiol-17 $\beta\left(\mathrm{E}_{2}\right)$ was determined, and it indicated hyperestrogenism $(42.05 \mathrm{pg} / \mathrm{mL})$ as against the reference values of $<15 \mathrm{pg} / \mathrm{mL}$ (Hornakova et al. (2017). Enzyme-linked immunosorbent assay was used to analyze antiMüllerian hormone (AMH) according to the manufacturer's descriptions (Accubind, Monobind Inc., U.S.A). AMH value was also increased $(25.50 \mu \mathrm{g} / \mathrm{mL})$, above the reference value of $<10 \mu \mathrm{g} / \mathrm{mL}$ (Hornakova et al. 2017).

Both radiographs (mobile X-ray machine, MDX-100 ${ }^{\mathrm{TM}}$, Chandigarh, India) and sonographs $\left(\mathrm{C}^{\circledR}{ }^{\circledR}\right.$ Laptop ultrasound machine, $5-8 \mathrm{MHz}$ transcutaneous probe; Sonostar ${ }^{\mathrm{TM}}$ Technologies Co., Ltd., Guangzhou, China) of the thoracoabdomino-pelvic regions revealed normal organ opacity and echogenicity, respectively, suggestive of the absence of metastases. Both transverse and longitudinal scrotal sonographs revealed diffuse non-homogenous tissues with increase in the echogenicity of the testicles. Abundant fibrosis and hydrocoele were also visualized.

\section{Medical Management}

The patient was hospitalised, and treatment commenced with Doxycycline hydrate at dose rate of $5 \mathrm{mg} / \mathrm{kg}$ PO BID + Normal Saline $\left(0.9 \% \quad \mathrm{NaCl}\right.$; BN $1039138 ;$ Unisal $^{\circledR}$, Unique Pharmaceuticals Ltd., Nigeria) IV infusion at $70 \mathrm{ml} / \mathrm{kg} / 24 \mathrm{hr}+$ Diclofenac Sodium injection (Fitzking ${ }^{\circledR}$, Jiangsu Huayang Pharmaceutical Co., Ltd., China) $4 \mathrm{mg} / \mathrm{kg}$ IM injection. Since rapid improvement was noticed soon after the institution of doxycycline treatment in the acutely-infected dog (Gaunt et al., 2010), the patient was scheduled for surgery in $72 \mathrm{hrs}$, enough time to stabilize and monitor the patient. Doxycycline hydrate was administered for at least 4 weeks (Mylonakis and 
Theodorou, 2017). The PCV improved (36\%) after 48 hours of hospitalization and institution of therapy. Vital parameters were back within referenced values except the rectal temperature which remained at $40{ }^{\circ} \mathrm{C}$, even after the dog resumed normal feeding and was ready for discharge. Even though, testis was enlarged with feminization syndrome, absence of bone marrow depression is an advantage to the success of the management.

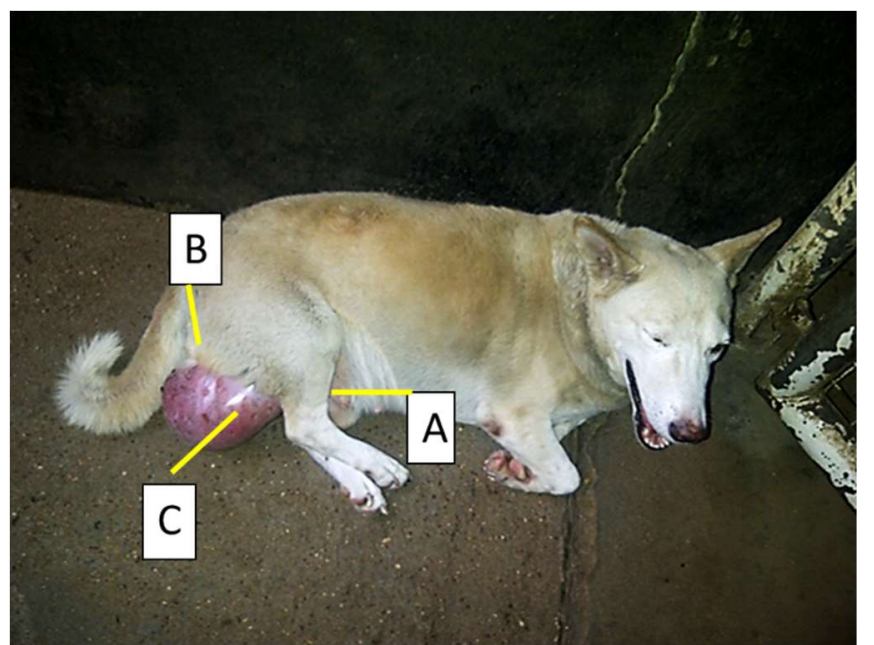

Figure 1: Sick dog hospitalised. A. enlarged mammary glands; B. alopecia; C. enlarged right scrotum with large, firm palpable mass that is warm to touch in the left testis.

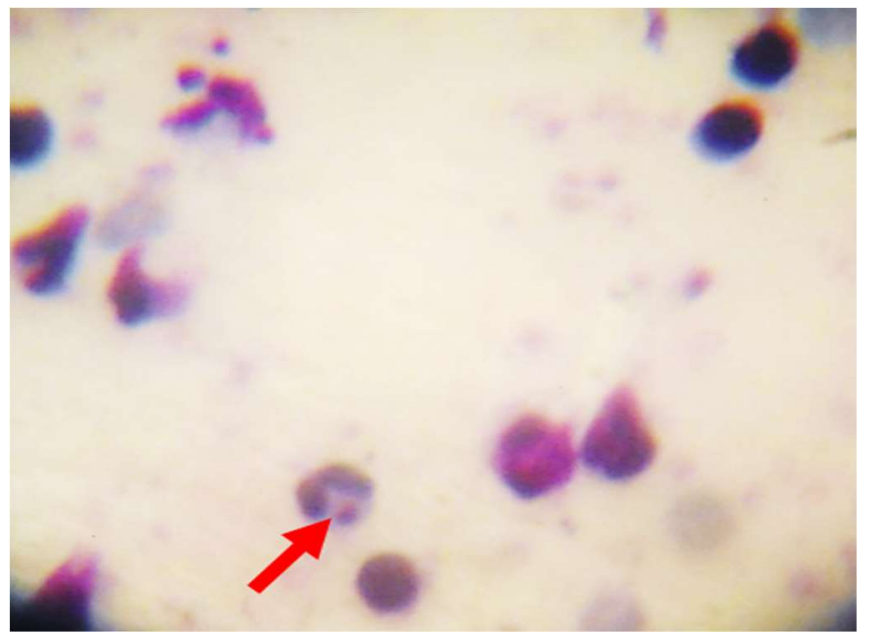

Figure 2: Presence of intracytoplasmic morulae in a monocyte (arrowed).

\section{Surgical Management}

The patient fed well a day before the surgery, and water was withheld for 3 hours before the surgery commenced. The animal was shaved and aseptically prepared for surgery. Premedication was achieved with atropine sulphate injection (AMOPIN, Ningbo Chemicals International Corporation, Ningbo, China) at $0.04 \mathrm{mg} / \mathrm{kg}$ body weight and Xylazine injection (Xylazine 20, Kepro, Holland) at $2 \mathrm{mg} / \mathrm{kg}$ body weight IM. Anaesthesia was induced using Propofol 1\% injection (Pofol, Popular Infusions Ltd., Bangledesh) at 6 $\mathrm{mg} / \mathrm{kg}$ body weight IV, and maintained with Ketamine hydrochloride (Jawa Ketamine, Swiss Parenterals PVT., India) injection $\mathrm{SC}$ at $11 \mathrm{mg} / \mathrm{kg}$.
Incision was made directly on the scrotum over the tumor mass. Subcutaneous tissue was also incised, and blunt dissection was used to exteriorise the entire testicle from the scrotum. The tunica vaginalis was then incised, and the testicle milked out of the tunic. The ductus deferens, spermatic cord and its structures were exposed, and haemostatic forceps were used to clamp the ductus deferens and the enlarged testicular artery. Proximal double ligation and single distal ligation with chromic gut size 2-0 (BECTON, Anhui Kangning Ind. Co. Ltd., Anhui, PRC) were made on the ductus deferens and testicular artery. The affected right testicle was then excised and removed (Figure 3). The same procedure was repeated on the contralateral shriveled testicle. The incision site was closed in two layers. The subcutaneous layer was closed with chromic cat gut size 2-0. Excess scrotal skin was trimmed off with scissors to remove dead space, and skin closure was achieved with interrupted suture pattern using nylon size 2-0 (LIFECARE, Anhui Kangning Ind. Co. Ltd., PCR). The patient was placed on Pentazocine injection (PENTAFORT, Pharmabase Nigeria Ltd.) at $3 \mathrm{mg} / \mathrm{kg}$ IV for 5 days. The diseased testicle measured $17 \times 11 \times 9 \mathrm{~mm}$, and weighed $0.8 \mathrm{Kg}$ (Figure 4). A section was cut $(>10 \mathrm{~mm}$ thick) from the diseased testis, fixed in $10 \%$ formaldehyde solution and submitted for histopathologic examination (Mohamed et al., 2017).



Figure 3: Exteriorised testicle, and tunica vaginalis and testicular artery clamped with haemostatic forceps and ligated.

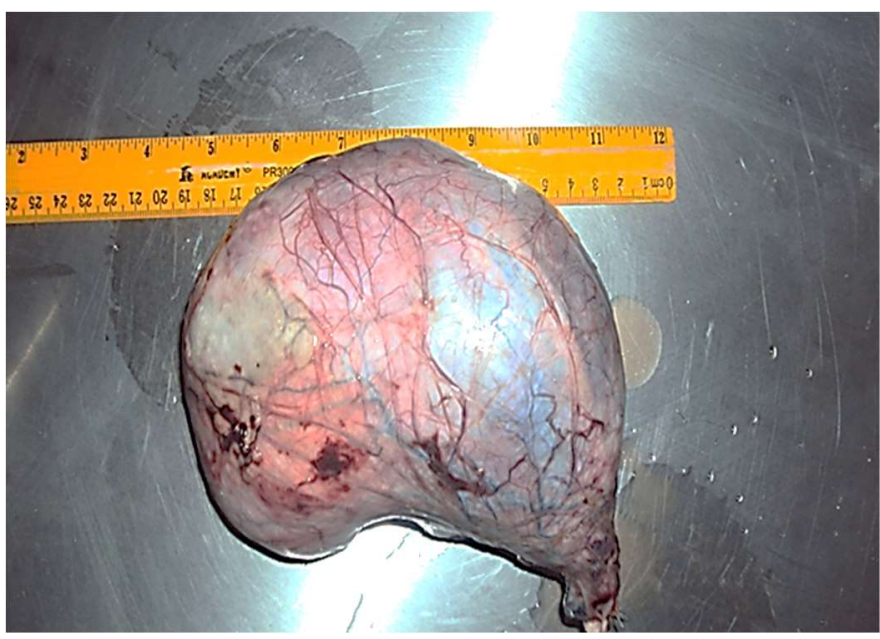

Figure 4: The diseased testis after castration measuring $17 \mathrm{x}$ $11 \times 9 \mathrm{~mm}$. 


\section{Histopathologic Findings}

Histopathologic examination revealed pale/clear cytoplasm with large cytoplasmic vacuoles, without significant nuclei and slightly irregular nucleoli. Mitosis was rarely observed (Figure 5).

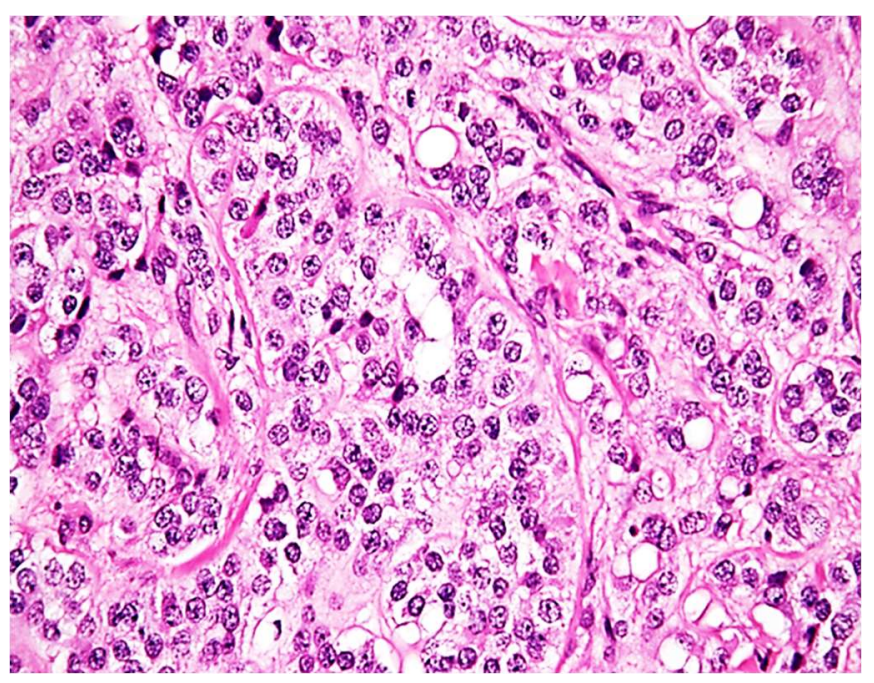

Figure 5: Group of cells in chords; Pale/clear cytoplasm with large cytoplasmic vacuoles, without significant nuclei and slightly irregular nucleoli, H\&E x 100.

\section{Re-evaluations}

Lateral flow assay was done every day for one week to monitor progress in the therapy determined by the absence of Ehrlichia canis antibody within the serum. Treatment failure or relapse could warrant change in chemotherapy (Mylonakis and Theodorou, 2017). The patient started feeding on gruel 24 hours after surgery even though, the rectal temperature was still high $\left(40^{\circ} \mathrm{C}\right)$. A week later, the patient was discharged.

The client was advised to adequately control and prevent tick infestation to reduce the risk of re-infection (Schaefer et al., 2007), and strictly adhere to therapeutic regimen (Doxycycline capsules orally for 4 weeks). In addition, he was asked to mix the drug with food in order to prevent unwanted effects of the drug (Schulz et al., 2011), and present the patient for evaluation when required. Sutures were removed 10 days after the surgery. Lateral flow assay was performed on days 14 and 28 post medical therapy. Another ultrasound and radiography were conducted on days 28 and 60 for metastasis of the tumour which was absent. Alopecia and feminization symptoms were resolved within 40 days of commencement of therapy.

\section{DISCUSSION}

The use of lateral flow assay (LFA) combined with buffy coat smear in the diagnosis of Canine Ehrlichiosis was justified in this case as reported by Harrus and Waner (2011) that serology is currently the mainstay for the confirmation of exposure to $E$. canis. This is usually recommended when prophylactic exposure is ruled out. Demonstration of Ehrlichia spp. morulae in monocytes, macrophages and lymphocytes in stained smears from whole blood or buffy coat, and less frequently in lymph node, bone marrow, spleen, liver and cerebrospinal fluid smears, is also helpful in establishing a definitive diagnosis of acute canine monocytic ehrlichiosis (CME) (Mylonakis et al.,
2010; Harrus et al., 2012; Kaewmongkol et al., 2016). Rapid improvement noticed shortly after the institution of doxycycline treatment is attributed to the acute course of ehrlichiosis in the patient. Although, doxycycline has been very effective in management of clinical and/or clinicopathologic ehrlichiosis in most experimentally and naturally infected dogs in acute or subclinical infections, it has not been invariably effective in completely eliminating $E$. canis infection in some cases as (Fourie et al., 2015; Schulz et al. 2011). Doxycycline was ineffective in dogs with chronic septicemia complicated with severe aplastic pancytopenia and severe bleeding (Mylonakis et al., 2004), and the use imidocarb dipropionate is no longer indicated in CME, except in dual infections with Babesia canis (Sainz et al., 2015). Even though, clinical and haemato-biochemical recovery can be seen just after one week of doxycycline therapy, but complete eliminati on of E. canis infection from blood can also be assessed by lateral flow assay in the absence of real-time PCR in order to detect the role of 21-28 days therapy with oral doxycycline in affected dogs.

History, clinical symptoms, determination of some serum biomarkers of tumour, full blood count, ultrasonography and radiography were all available and employed as diagnostic tools for SCT, and a definitive diagnosis was based on histological examination of the removed tissue sample (Carreira et al., 2012). Although the normal hormonal profiles for the patient were not determined prior to the presentation, the hormones assayed for, as expected, were much higher than the reference values (Hornakova et al., 2017). The hyperestrogenism is indicative of functional SCT, and was manifested as feminization syndrome as presented in the patient (Quartuccio et al., 2012).

\section{Conclusion}

A readily available oral doxycycline, can be used as a specific drug in treating acute canine monocytic ehrlichiosis, and benign Sertoli cell tumour can be managed by orchidectomy and scrotal ablation.

\section{Conflict of Interest}

The authors declare that they do not have any conflict of interest.

\section{Author Contribution}

RAM received and clerked patient, instituted medical treatments, and recommended patient for surgery. RAM and AA wrote the first draft of this manuscript. ML and BU-S carried out diagnostic imaging and haemoparasitic diagnosis, respectively, as well as interpretation of the results. EGE, MA, SS and AA performed orchidectomy and scrotal ablation. They made inputs on the surgical procedures, anaesthesia and postoperative managements. JS performed tissue sectioning, histopathologic stain and interpretation of the result. All authors read and approved the final manuscript.

\section{REFERENCES}

Banco, B., Veronesi, M.C, Giudice, C., Rota, A., Grieco, V. (2012). Immunohistochemical evaluation of the expression of Anti-Müllerian Hormone in mature, 
immature and neoplastic Canine Sertoli cells. J. Comp. Path., 146(1): 18-23

Cahua, U.J., Sandoval, C.N., Fernández, A.V. Puicón, N.V. (2015). Pyometra and Sertoli cell tumor in a dog with persistent Müller duct. Rev. Invest. Vet. Perú (RIVEP), 26(4): 705-711

Carreira, V.S., Langohr, I.M., Ferrari, H.F., Rui Luvizotto, M.C. (2012). Pathology in practice: Sertoli cell tumor (SCT). J. Am. Vet. Med. Assoc., 241(1): 55-57

Castro, J.L.C., Albernaz, V.G.P., Domingues, C.M.T., Ferreira, A.A., Dittrich, G., Moratelli, C.B.S., Freitag, F.V. Miara, L.C. (2016). Malignant Sertoli cell tumor with abdominal infiltrative metastasis in a dog. Pak. Vet. J., 36(3): 379-381

Dhliwayo, S., Chihambakwe, B., Taonezvi, K., Chikerema, S.M., Tivapasi, M.T. and Pfukenyi, D.M. (2019). Seroprevalence of Canine Ehrlichiosis and Microscopic Screening for Canine Babesiosis in Dogs in Harare, Zimbabwe, 2016-2017. Vet. Med. Int., Article ID 4130210, https://doi.org/10.1155/2019/413 0210

Ferguson, L. and Agoulnik, A.I. (2013). Testicular cancer and cryptorchidism. Front. Endocrinol., 4 (32): 1-9

Fourie, J.J., Horak, I., Crafford, D., Erasmus, H.L., Botha, O.J. (2015). The efficacy of a generic doxycycline tablet in the treatment of Canine monocytic Ehrlichiosis. J. S. Afr. Vet. Assoc., 86:1193

Gaunt, S., Beall, M., Stillman, B., Lorentzen, L., Diniz, P., Chandrashekar, R. Breitschwerdt, E. (2010). Experimental infection and co-infection of dogs with Anaplasma platys and Ehrlichia canis: hematologic, serologic and molecular findings. Para. \& Vect., 3 (1): 33

Grieco, V., Riccardi, E., Greppi, G.F., Teruzzi, F., Iermano, V., Finazzi, M. (2008). Canine testicular tumours: a study on 232 dogs. J. Comp. Pathol., 138(2): 86-89

Harrus, S., Warner, T., Neer, M. (2012). Ehrlichia canis infection. In: Sykes, J. and Greene, C., (Eds.) Infectious Diseases of the Dog and Cat. Elsevier Saunders, St. Louis, Missouri, pp. 227-238

Harrus, S. and Waner, T. (2011). Diagnosis of Canine monocytotropic Ehrlichiosis (Ehrlichia canis): an overview. Vet. J., 187: 292-296

Herndon, A.M., Casal, M.L., Jaques, J.T.S. (2012). Testicular neoplasia in the retained testicles of an intersex male dog. J. Am. Anim. Hosp. Assoc., 48(2): 118-124

Hohsteter, M., Artus kovic, M., Severin, K., Kurilj, A.G., Beck, A., Sostaric-Zuckermann, I.C., Grabarevic, Z. (2014). Canine testicular tumors: two types of seminomas can be differentiated by immunohistochemistry. Vet. Res., 10: 1-9

Holst, B.S. and Dreimanis, U. (2015). Anti-Müllerian hormone: a potentially useful biomarker for the diagnosis of canine Sertoli cell tumours. BMC Vet. Res., 11: 166-172

Hornakova, T., Vrbovska, M., Pavlak, A., ValencakovaAgyagosova, M., Halo, J. H. (2017). The evaluation of blood concentrations of testosterone, 17 $\beta$-oestradiol and anti-Mullerian hormone in $\operatorname{dogs}$ with cryptorchidism and testicular tumours. Pol. J. Vet. Sci., 20(4): 677-685

Jain, N.C. (1986). Schalm's Veterinary Haematology. $4^{\text {th }}$ Edition, Lea and Febiger, Philadelphia, U.S.A., pp. 5890

Kaewmongkol, G., Maneesaay, P., Suwanna, N., Tiraphut, B., Krajarngjang, T., Chouybumrung, A., Kaewmongkol, S., Sirinarumitr, T., Jittapalapong, S., Fenwick, S.G. (2016). First Detection of Ehrlichia canis in cerebrospinal fluid from a non-thrombocytopenic dog with meningo-encephalitis by broad-range PCR. J. Vet. Intern. Med., 30(1): 255-259

Kang, S.C., Yang, H.S., Jung, J.Y., Jung, E.H., Lee, H.C. (2011). Malignant Sertoli cell tumor in Shih Tzu dog. Korean J. Vet. Res., 51:171-175

Kottadamane, M.R., Dhaliwal, P.S. and Singla, L.D. (2016). Diagnosis and treatment of canine monocytic ehrlichiosis in a boxer breed of $\operatorname{dog}$ - a case report. Intern. J. Sci. Envt. Tech., 5(5): 3099 - 3105

Kukreti, K., Das, M.K., Rastogi, A.K., Dubey, R., Pandey, L.K. and Sharma, P. (2018). Prevalence of Canine Monocytic Ehrlichiosis in Canine Population Across India. Arch. Razi Inst., 73(2): 87-93

Lawrence, J.A. and Saba, C.F. (2013). Tumors of the male Reproductive system. In: Withrow and MacEwen (Eds.) Small Animal Clinical Oncology. Elsevier Saunders, USA, pp. 557-571

Liao, A.T., Chu, P.Y., Yeh, L.S., Lin, C.T., Liu, C.H. (2009). A 12-year retrospective study of canine testicular tumors. J. Vet. Med. Sci., 71(7): 919-923

Mohamed, S., Bauchet, A-L., Fiette, L. (2017). Tissue sampling and processing for histopathology evaluation. Histopathology procedures. In: Gautier, JC. (Ed.) Drug Safety Evaluation: methods and protocols, methods in molecular biology. Springer Science+Business Media LLC, pp. 101-114

Mylonakis, M.E., Koutinas, A.F., Breitscwerdt, E.B., Hegarty, B.C., Billinis, C.D., Leontides, L.S.and Kontos, V.S. (2004). Chronic Canine ehrlichiosis (Ehrlichia canis): a retrospective study of 19 natural cases. J. Am. Anim. Hosp. Assoc., 40(3): 174-184

Mylonakis, M.E., Siarkou, V. and Koutinas, A.F. (2010). Myelosuppressive canine monocytic ehrlichiosis (Ehrlichia canis): An update on the pathogenesis, diagnosis and management. Isr. J. Vet. Med., 65(4):129-134

Mylonakis, M.E. and Theodorou, K.N. (2017). Canine monocytic ehrlichiosis: an update on diagnosis and treatment. Acta Vet-Beograd, 67(3): 299-317

Priyadarshini, M., Veena, J.D., Carunya, R., Mannan, H. L., Rastogi, D.P. (2019). Ovarian Sertoli-Leydig cell tumor with estrogenic manifestations in a postmenopausal lady: a case report. Indian J. Surg. Oncol., 10(3): 499-501

Quartuccio, M., Marino, G., Garufi, G., Cristarella, S., Zanghì, A. (2012). Sertoli cell tumors associated with feminizing syndrome and spermatic cord torsion in two cryptorchid dogs. J. Vet. Sci., 13(2): 207-209

Rabban, J.T., Soslow, R.A and Zaloudek, C.Z. (2010). Immunohistology of the female genital tract. In: 
Dabbs, D. J. (Ed.) Diagnostic immunohistochemistry, theranostic and genomic applications. Elsevier Inc., pp. 690-762

Sainz, A., Roura, X., Miro, G., Estrada-Pena, A., Kohn, B., Harrus, S. and Solano-Gallego, L. (2015). Guidelines for veterinary practitioners on canine ehrlichiosis and anaplasmosis in Europe. Para. \& Vect., 8:75

Schaefer, J.J., Needham, G.R., Bremer, W.G., Rikihisa, Y., Ewing, S.A., Stich, R.W. (2007). Tick acquisition of Ehrlichia canis from dogs treated with doxycycline hyclate. Antimicrob. Agents \& Chemother., 51: 33943396

Schulz, B.S., Hupfauer, S., Ammer, H., Sauter-Louis, C., Hartmann, K. (2011). Suspected side effects of doxycycline use in dogs - a retrospective study of 386 cases. Vet. Rec., 169(9): 229

Sivasudharsan, L., Devarathan, J., Mahesh, R., Kamalalar, G., Rambabu, K., Sumiran, N. and Sailaja, N. (2017). Sertoli cell tumor in a dog: a case report. Indian J. Canine Pract., 9(1): 75-77

Švara T, Gombač M, Pogorevc E, Plavec T, Zrimšek P, Pogaenik M. A. (2014). Retrospective study of canine testicular tumors in Slovenia. Slov. Vet. Res., 51:8188
Tsuzuki, Y., Kikuchi, I., Nojima, M., Yoshida, K., Hashizume, A., Tomita, S. (2017). A case report: ovarian Sertoli-Leydig cell tumor with hyperestrogenism and endometrial hyperplasia in a postmenopausal woman. Jpn. J. Clin. Med., 8: 1179066017695239

Valente, P.C.L.G., Couto, R.M., Gamba, C.O., Vasconcelos, A.V., Leme, F.O.P, Ecco, R. and Paes, P.R.O. (2017). Bone marrow bi-hypoplasia in a dog with a sertoli cell tumor. Arq. Bras. Med. Vet. Zootec., 69(1): 95-100

Waner, T. and Harrus, S. (2013). Canine monocytic ehrlichiosis: from pathology to clinical manifestations. Isr. J. Vet. Med., 68:12-18

Young,R.H. (2005). Sex cord-stromal tumors of the ovary and testis: their similarities and differences with consideration of selected problems. Mod Pathol., 18: S81-S98

Zambarda, T.T., Renata, Q. S., Sonne, L., Pöppl, A.G. (2019). Müller's duct persistence syndrome associated with cryptorchidism, sertoli cell tumor and pyometra in a miniature schnauzer - a case report. Acta Sci. Vet., 47(1): 446-451 